\title{
Theory-of-Mind Continuum Model: Why Mind Matters in Philosophy, Psychology and Education
}

\author{
Yoon-Suk Hwang, The University of Sydney, NSW, Australia \\ David Evans, The University of Sydney, NSW, Australia \\ Jim Mackenzie, The University of Sydney, NSW, Australia
}

\begin{abstract}
Theory-of-Mind has been defined as the ability to explain and predict human behaviour by imputing mental states, such as attention, intention, desire, emotion, perception and belief, to the self and others (Astington \& Barriault, 2001). Theory-of-Mind study began with Piaget and continued through a tradition of meta-cognitive research projects (Flavell, 2004). A study by Baron-Cohen, Leslie and Frith (1985) of Theory-of-Mind abilities in atypically developing children reported major difficulties experienced by children with autism spectrum disorder (ASD) in imputing mental states to others. Since then, a wide range of follow-up research has been conducted to confirm these results. Traditional Theory-of-Mind research on ASD has been based on an either-or assumption that Theory-of-Mind is something one either possesses or does not. However, this approach fails to take account of how the ASD population themselves experience Theory-of-Mind. This paper suggests an alternative approach, Theory-of-Mind continuum model, to understand the Theory-of-Mind experience of people with ASD. The Theory-of-Mind continuum model will be developed through a comparison of subjective and objective aspects of mind, and phenomenal and psychological concepts of mind. This paper will demonstrate the importance of balancing qualitative and quantitative research methods in investigating the minds of people with ASD. It will enrich our theoretical understanding of Theory-of-Mind, as well as contain methodological implications for further studies in Theoryof-Mind.
\end{abstract}

Keywords: Theory-of-Mind, Autism Spectrum Disorder, Phenomenal Mind, Psychological Mind, Interdisciplinary Approach to Mind, Ontology, Epistemology, Developmental Psychology, Special Education

$\mathrm{T}$ HEORY-OF-MIND HAS BEEN defined as the ability to explain and predict human behaviour by imputing mental states, such as attention, intention, desire, emotion, perception and belief, to the self and others (Astington \& Barriault, 2001). Along with executive function, it is seen as one of two major cognitive theories that can explain the uniqueness of autism spectrum disorder (ASD) (Ozonoff \& McEvoy, 1994). Theoryof-Mind study grew over a 20 year period to be "one of the largest and liveliest in development psychology" (Flavell, 2004, p 274). This area of study is located within the intersection of psychology, philosophy and special education. Philosophy has enriched the theoretical aspects of Theory-of-Mind study in psychology, while psychology has put these theories to the test through scientific experiments. Special education, meanwhile, seeks to turn philosophical and psychological understanding into practical strategies to assist students with disabilities in their development as human beings.

Within the field of psychology, Theory-of-Mind theorists have attempted to understand how the minds of people with disabilities, mainly ASD, differ from the norm, and in particular whether or not they possess Theory-of-Mind ability. As a consequence, a general agreement has emerged that people with ASD have either no or a severely limited Theory-ofMind ability. This is the deficit approach to Theoryof-Mind. It began with the study by Premack and Woodruff (1978) that resulted in the claim that a chimpanzee possesses Theory-of-Mind. Subsequent researchers have argued that the majority of children with ASD do not possess Theory-of-Mind (BaronCohen, Leslie \& Frith, 1985). However, while this deficit, either/or approach to Theory-of-Mind provided a starting point for research, it contains certain limitations that need to be overcome if our understanding is to develop. In particular, the deficit approach to Theory-of-Mind has influenced intervention studies, and the emergence of more effective teaching interventions for children with ASD requires that our understanding of Theory-of-Mind be further developed.

While social scientists may feel that their job is completed once they establish that certain children experience a deficit of Theory-of-Mind, this just marks the starting point for special educationalists. Special educationalists use Theory-of-Mind study to develop interventions that can improve Theoryof-Mind understanding in their students, and provide strategies for them to overcome particular limitations. 
This paper is an investigation of Theory-of-Mind from the perspective of special education. It seeks to enrich our theoretical and methodological understanding of Theory-of-Mind by critiquing existing Theory-of-Mind studies from a philosophical, psychological and educational perspective. This understanding has the potential to provide new insights for creating effective educational interventions for students with disabilities. This paper therefore proposes a Theory-of-Mind continuum model that takes an interdisciplinary approach and, most importantly, keeps in mind the question, "What is good for children?"

\section{History of Theory-of-Mind Study}

The actual term "Theory-of-Mind" in psychology began with the study of cognition and consciousness in nonhuman species conducted by Premack and Woodruff (1978), who demonstrated that an adult chimpanzee has the capacity to infer mental states. Despite criticisms by Dennett (1978) and Pylyshyn (1978), this study inspired further research in cognitive development psychology in the following areas: (1) the developmental course of Theory-of-Mind in typically developing children; and (2) Theory-ofMind abilities in atypically developing children.

A number of researchers have studied the core concepts of Theory-of-Mind and their developmental sequences in typically developing children (e.g., Astington, 1994; Frye, 1991; Gopnik, Slaughter, Meltzoff, 1994; Leekam et al., 1997). Studies have also focused on the skills and experiences that affect Theory-of-Mind understanding, such as language, social competence, executive function, and the impact of siblings (e.g., Bosacki \& Astington, 1999; Dorris, Espie, Knott, \& Salt, 2004; German \& Hehman, 2006; Sparrevohn \& Howie, 1995).

Theory-of-Mind abilities of children with ASD and intellectual disabilities were investigated in a pioneering study by Baron-Cohen, Leslie and Frith (1985). This study reported that children with ASD significantly lack Theory-of-Mind. Since then, a wide range of follow-up research has been conducted to confirm this result (e.g., Baron-Cohen, Campbell, Darmiloff-Smith, Grant, \& Walker, J., 1995; Leekam et al., 1997; Jolliffe, \& Baron-Cohen, 1999). In addition, intervention studies have examined the related issue of the capacity of atypically developing children to improve their Theory-of-Mind understanding (e.g., Bauminger, 2002; Chin \& Bernard-Opitz, 2000).

\section{Theory-of-Mind and Its Connection with Philosophy of Mind}

Theory-of-Mind study has been bound up with philosophy of mind from the beginning. The philo- sophers Pylyshyn (1978) and Dennett (1978) criticised Premack and Woodruff's pioneering study of Theory-of-Mind, arguing that the establishment of Theory-of-Mind abilities requires clear evidence of second order mental representation capacities, or meta-representation. For example, if two people $a$ and $b$ understood a situation to be a certain way, and this situation was changed in the absence of person $b$, then person $a$ 's capacity to understand that person $b$ 's belief about that situation was now false would show that person $a$ was able to objectify their own mental processes - in other words, to demonstrate a meta-representation capacity.

Wimmer and Perner (1983) developed "Maxi's story" to test for this ability. The first false belief task, Maxi's story began a trend among researchers to test for Theory-of-Mind by looking for the capacity for meta-representation in subject populations.

The issue of meta-representation then became entangled with that of "folk psychology." Fodor (1985) attempted to articulate a theory of commonsense or folk psychology in which he argued that propositional attitudes as normally understood, such as belief and desire, constitute an empirical foundation for imputing a Theory-of-Mind to a person. He believed that such propositional attitudes have causal powers (e.g., thoughts cause desires). Fodor's view influenced Theory theorists. Gopnik (1996) used folk psychology as a starting point for a scientific psychology and put forward a child-as-scientist account of Theory-of-Mind acquisition. Meltzoff (1999) said that like adult scientists, children actively struggle to make sense of the information they are given through collaboration with others in the social environment. Bartsch and Wellman (1995) explained children's development of Theory-of-Mind with a three step model, beginning with a desire psychology, moving towards a desire-belief psychology, and ending in a belief-desire psychology.

Other Theory-of-Mind theorists, known as modularity theorists, also took up Fodor's work, highlighting his contention that discrete computational-representational systems underlie human cognition (Fodor, 1985), each representing a distinct module of mental function (Fodor, 1983). These ideas were taken up by Leslie (1988) and Baron-Cohen (1995). Leslie claimed that specific innate mechanisms, Theory of Mind Modules (ToMM), develop Theory-of-Mind and these mechanisms work to generate pretend play in the early stage of a child's life. Baron-Cohen also proposed eye-direction detector (EDD), shared-attention mechanism (SAM) and intentionality detector (ID) as companion mechanisms for ToMM to function for the human mindreading system.

As Ravenscroft (2005) mentions, in the field of cognition studies the boundary between philosophy and psychology is vague. Theory-of-Mind in psycho- 
logy began and evolved in relationship with philosophy, especially philosophy of mind. In the following section we will discuss the influence of Theoryof-Mind on special education.

\section{Theory-of-Mind and its Influence on Special Education}

Since the early work of Baron-Cohen et al. (1985), Does the autistic child have a theory of mind?, reported that children with ASD have major difficulties imputing mental states to others, a number of studies have supported this view and have concluded that children with ASD have either no or a severely limited Theory-of-Mind ability (e.g., Baron-Cohen et al., 1995; Jolliffe \& Baron-Cohen, 1999; Leekam et al., 1997). The belief that children with ASD suffer from a "deficit" of Theory-of-Mind has since become general. Baron-Cohen, for example, has relied on tests for Theory-of-Mind to identify early childhood ASD (1995).

Theory-of-Mind studies have contributed to our understanding of the social-cognitive difficulties of children with ASD. Modularity theorists see damaged ToMM (Baron-Cohen, 1995), theory theorists suggest the absence of the initial theory and/or a theoryformation deficit (Gopnik, Capps, \& Meltzoff, 2000), and simulation theorists, who look at a person's capacity to project themselves into another person's situation, suspected insufficient capacity to imagine (Carruthers \& Smith, 1996) as reasons for Theoryof-Mind problems in this population. At the same time, an emphasis on this line of research raises a number of problems in special education. Firstly, it generates a tendency to limit the universality of Theory-of-Mind problems, seeing them as unique to the ASD population. Secondly, it creates an undue emphasis on a "deficit" approach in Theory-of-Mind understanding. Thirdly, it places an imbalanced emphasis on the role of false belief.

Limits on the universality of Theory-of-Mind problems the tendency to assume that difficulties in Theory-of-Mind understanding is peculiar to people with ASD has been challenged by meta-analyses comparing Theory-of-Mind among populations with ASD, intellectual disabilities, and typically developing children. These meta-analyses reveal that people with intellectual disabilities also demonstrate delayed
Theory-of-Mind development in comparison with typically developing children (Yirmiya, Erel, Shaked, \& Solomonica-Levi, 1998). So also do children with hearing impairments or deafness (Peterson \& Siegal, 2000), as well as children who are severely visually impaired or blind (McAlpine \& Moore, 1995; Peterson, Peterson \& Webb, 2000). These examples raise doubts regarding the degree to which difficulty with Theory-of-Mind understanding is limited to people with ASD (Yirmiya et al., 1998).

$A$ "deficit" approach in Theory-of-Mind Evidence from developmental studies highlights the importance of taking a developmental perspective on Theory-of-Mind, and this brings into doubt the emphasis on Theory-of-Mind as a given "deficit," or "mindblindness," possessed by people with ASD (Baron-Cohen, 1995). Some children with ASD have "passed" Theory-of-Mind performance tests (Happé, 1994) following the same developmental sequences as typically developing children (Sparrevohn \& Howie, 1995). A longitudinal study with 57 children with ASD (Steele, Joseph, \& Tager-Flusberg, 2003) also reported significant developmental improvement in Theory-of-Mind. One important Theory-of-Mind component is pretence, and Bergen (2002) has demonstrated how engagement in pretence with typically developing peers creates positive changes in pretence abilities for children with ASD.

Is false belief Theory-of-Mind? Finally, undue emphasis on the importance of false belief (based on Dennett and Pylyshyn's criticisms of Premack and Woodruff's pioneering study) may hinder our understanding of Theory-of-Mind. Since Wimmer and Perner (1983), false belief tasks have become the litmus test to indicate the presence or absence of Theory-of-Mind, and as a result research focuses on the representational, or cognitive, mental states of belief and knowledge to the detriment of the study of other mental states, such as intention, perception and desire (Hughes \& Leekam, 2004). Eight out of a total 15 studies that claimed to evaluate Theoryof-Mind understanding among the ASD population used a single mental state, false belief, to indicate Theory-of-Mind understanding (see Table 1). Astington (2001) warned that "it is dangerous a single task becomes a marker for a complex development ( $p$ 687)." She distinguishes false belief from Theoryof-Mind, and emphasises the importance of other mental states for Theory-of-Mind research. 
Table 1: Summary of Evaluation of Theory-of-Mind Understanding Reviewed

\begin{tabular}{|c|c|c|c|c|c|}
\hline No & Author & Mental states & No & Author & Mental states \\
\hline 1 & $\begin{array}{l}\text { Baron-Cohen et al. } \\
\text { (1985) }\end{array}$ & False belief & 2 & Bauminger \& Kasari (1999) & False belief \\
\hline 3 & Blackshaw et al. (2001) & $\begin{array}{l}\text { Thoughts, emotions } \\
\text { of others }\end{array}$ & 4 & Brent et al. (2004) & $\begin{array}{l}\text { False belief, inten- } \\
\text { tion, humour, } \\
\text { thoughts, emotions, }\end{array}$ \\
\hline 5 & Brown \& Whiten (2000) & $\begin{array}{l}\text { Joint attention, em- } \\
\text { pathy, manipulation } \\
\text { of others' mental } \\
\text { states }\end{array}$ & 6 & $\begin{array}{l}\text { Charman \& Baron-Cohen } \\
\text { (1995) }\end{array}$ & False belief \\
\hline 7 & Frith et al. (1994) & False belief & 8 & Happé (1994) & $\begin{array}{l}\text { Pretend, joke, lie, } \\
\text { double bluff, False } \\
\text { belief etc. }\end{array}$ \\
\hline 9 & Kerr \& Durkin (2004) & False belief & 10 & Ozonoff \& McEvoy (1994) & False belief \\
\hline 11 & Sally \& Hill (2006) & False belief & 12 & Sicotte \& Stemberger(1999) & False belief \\
\hline 13 & $\begin{array}{l}\text { Sparrevohn \& Howie } \\
\text { (1995). }\end{array}$ & Belief, false belief & 14 & Steele et al. (2003) & $\begin{array}{l}\text { Pretend, desire, per- } \\
\text { ception, knowledge, } \\
\text { false belief, lies, } \\
\text { jokes, moral judge- } \\
\text { ment, traits }\end{array}$ \\
\hline 15 & $\begin{array}{l}\text { Swettenham et al. } \\
\text { (1996) }\end{array}$ & $\begin{array}{l}\text { False belief, } \\
\text { thoughts }\end{array}$ & & & \\
\hline
\end{tabular}

The tendency to emphasise false belief has affected the nature of Theory-of-Mind intervention studies for atypically developing populations. Three main patterns can be seen in these studies, all of which involve false belief. The first category of study teaches Theory-of-Mind through false belief tasks, and looks for evidence of improvement by means of success in false belief tasks (e.g., McGregor, Whiten \& Blackburn, 1998). A second category of study teaches Theory-of-Mind through false belief tasks (either alone or along with other tasks), and looks for evidence of improvement by means of skills thought to be linked to Theory-of-Mind, such as language and social skills (e.g., Hadwin, Baron-Cohen, Howlin, \& Hill, 1997; Ozonoff \& Miller, 1995). A third category of study teaches these associated skills and looks for evidence of improvement in Theory-of-Mind by means of false belief tasks (e.g., Chin \& Bernard-Opitz, 2000).

The tendency to base Theory-of-Mind research regarding the ASD population on the either-or assumption that Theory-of-Mind is something one either possesses or does not fails to shed light on how the ASD population themselves experience Theory-of-Mind. The following section will discuss the different ways in which the mind and its relationship to the world can be viewed. The variety of approaches indicates the need for a more varied and flexible approach to researching Theory-of-Mind.

\section{Back to Philosophy}

Broadly speaking, the study of the human condition can emphasise ontology or epistemology; it can be approached through objectivity or subjectivity; and it can rest upon psychological or phenomenal concepts of mind. This variety of views and approaches indicates the necessity for a multidisciplinary approach to the study of Theory-of-Mind, embracing a variety of research methods. It also opens up the possibility of a more complex Theory-of-Mind continuum model, rather than a simple either-or, deficit or surplus, approach to Theory-of-Mind.

Ontology and epistemology The western philosophical tradition recognises two main ways of viewing reality: ontology and epistemology. Ontology deals with the nature and structure of what is really there available to be known. It is about "what we know" rather than "how we know." Epistemology, in contrast, deals with the nature and sources of knowledge itself (Grayling, 1995; O’Connor \& Carr, 1982). It is about "how we know" rather than "what we know."

An ontological approach to understanding reality assumes the independent existence of objects or ideas. Things in the world are not dependent on the knower for their reality (Cohen, Manion, \& Morrison, 2002). Reality is something that is "out there," waiting to be discovered. An epistemological ap- 
proach to understanding cannot escape the influence of the process of knowing itself, and therefore remains bound up with the knower. Reality is "in here," as well as "out there," and is found in the relationships between these two poles of experience (Glasersfeld, 1995). A study that focuses on the presence or absence of Theory-of-Mind, for example, shows an approach that is more ontological than epistemological - Theory-of-Mind is "there," or not.

Objectivity and subjectivity This distinction between ontology and epistemology is bound up with that between objectivity and subjectivity. That which objectively exists is "there," regardless of a person's experience of it. It can be quantitatively measured, and these measurements, if accurate and adequately analysed, constitute real, even "scientific" knowledge. But if, as in epistemology, the process of knowing itself becomes central, then the knowledge gained is closer to subjectivity and further from what is normally regarded as science.

Nagel (1986) points out that objectivity and subjectivity do not refer to two different ontological realms, but to different methods of understanding. For him, a view of the world becomes more objective the more it abandons an individual perspective and becomes available to others. A view of the world becomes more subjective the more it remains dependent on the perspective of the individual (Nagel, 1986). Ultimate objectivity would be a view in which the viewer is eliminated altogether. Yet, as Nagel warns, "there are things about the world and life and ourselves that cannot be adequately understood from a maximally objective standpoint." (1986, p.7)

Objective methods of understanding are seen as resulting in knowledge that is public, open to all. However, the price for attaining universality may be the loss of the felt sense of experience, what it is like to have a particular experience - such as Theory-ofMind - that is contained within subjectivity. Subjective methods of understanding, in contrast, while characterised by the felt sense of what it is like to experience something from a particular perspective, may be regarded as leading to knowledge that is private, unique to the individual, and so not appropriate to public discourses such as the social sciences (Pring, 2000).

The field of education and educational research could be seen as located between the realms of subjectivity and objectivity, placing value on both. Education establishes a continuum between the subjective and the objective, as education mediates between publicly held knowledge on the one hand, and the personal questioning of young people on the other (Pring, 2000).

Concepts of mind The distinctions between subjective and objective methods of understanding the mind and its interface with the world are in turn re- lated to two distinct concepts of mind, which Chalmers (1996) calls the psychological and the phenomenal. A psychological concept of mind is concerned with behaviour, observed from a third person perspective, and seeks causal explanations for actions observed and measured objectively. Mind is characterised by what it does. A phenomenal concept of mind is concerned with conscious experience, felt from within, subjectively, from a first person perspective. Mind is characterised by the way it feels (Chalmers, 1996).

These concepts of mind, and the knowledge they give rise to, are not opposed to each other. Rather, they provide different views into the same phenomenon. Minds can be studied causally; there is a relationship between mind and behaviour. Yet, any study of behaviour that remains blind to what it feels like to undergo such behaviour misses something vital to understanding that behaviour.

Methodological considerations Establishing Theory-of-Mind understanding requires an approach that can embrace the complexity of the task. The mind's complexity raises two issues related to the methodological problems of testing and teaching Theory-of-Mind: how to measure Theory-of-Mind understanding; and which component(s) of Theoryof-Mind can indicate the presence of this understanding.

As we have seen above, some studies have used false belief as the single touchstone, claiming that an inability to pass false belief tests is enough to establish the absence of Theory-of-Mind (e.g., BaronCohen et al., 1985). However, while the capacity to pass false belief tasks in an experimental setting is adequate for a causal, psychological understanding of the mind, it may be inadequate for a phenomenal understanding, for that entails multiple individual realities. It follows that understanding the complex phenomenon that is the human mind requires a variety of research methods, including qualitative and phenomenological approaches.

Further, an over emphasis on understanding the false beliefs of others to establish Theory-of-Mind neglects the role of understanding the desires or intentions of others. Understanding the false belief of others is more difficult than understanding their desires and intentions (Astington \& Barriault, 2001; Astington, 2001). Passing false belief tasks is related to verbal linguistic ability (Sparrevohn \& Howie, 1995) and executive function (Ozonoff \& McEvoy, 1994). Attention and motivation are also required to follow scenarios of false belief tasks. Are we to conclude that people who understand the desires of others but not their false beliefs have no Theory-ofMind understanding? Rather, it would appear that we need a more flexible methodological approach to understanding Theory-of-Mind. 


\section{Theory-of-Mind Continuum Model - Theoretical Aspects}

Theory-of-Mind entails the ability to be aware of one's own world and simultaneously to infer that of others. Our direct awareness of our own world is subjective, private and phenomenal. Our inferential understanding of the world(s) of others is objective, public and causal. Theory-of-Mind therefore requires an ability to move between subjectivity and objectivity.

Rather than seeing this ability in terms of a simple "either-or" polarity, it may be more usefully viewed as a continuum. This continuum is based on two poles, space and depth. "Space" here refers to the movement of awareness between the inner space of a person's subjective world to the external space of the objectively shared world of others, and the capacity to simultaneously maintain an awareness of both. Space therefore contains three movements: from inner to outer; from outer to inner; and holding both, simultaneously. "Depth" refers to the degree to which a person understands the differences and similarities between their own inner, subjective mental processes and those of others.

The mental processes in question may be desires, intentions, beliefs, and so on. Some of these states are more difficult to infer than others, requiring a greater degree of depth to understand them. A person's ability to recognise similarities and differences in specific mental states may therefore vary, depending on which mental state is in question, and how freely the person moves between the inner and the outer.

Underlying these two poles of space and depth is the developmental aspect of Theory-of-Mind. Over time, a person's experience of these poles can improve, or regress. An example of improvement would be a case where an adult with ASD discovered how to comfort herself through physical contact, and through that learned to comfort her cat. This is something she could not do as a child (Grandin, 2006). In other words, the Theory-of-Mind continuum model itself models a continuum within a subject.

\section{Theory-of-Mind Continuum Model - Methodological Aspects}

This model proposes the hypothesis that Theory-ofMind describes a complicated and contiguous continuum between the lived experience of subjectivity and objectivity found within a mind, and no single method alone can adequately deal with this complexity. More fundamentally, Theory-of-Mind study concerns mind, and mind is internally experienced rather than directly observable. Its everyday, continuous experiences cannot be captured only through objective and quantitative methods such as false belief tasks. Therefore this study recommends supplementing objective research methods with qualitative ones. Baron-Cohen (1995) himself acknowledged the centrality of first person experience for Theoryof-Mind research, although he thought that children with autism might lack the self-reflexivity to be aware of their first person experience.

Taking first person experience seriously has implications for Theory-of-Mind experiments. For example, in his book "Send in the idiots" Nazeer (2006), an adult with ASD, expressed doubt about the reliability of false belief task experiments for children with ASD. These tasks are designed in such a way that they begin with the child giving an answer to a question that turns out to be wrong, followed by the demand to try again. Nazeer suspects such experiments could be tainted by the anxiety they create in autistic children, although other children would not be so affected. Another autistic adult, Temple Grandin (2006), in her book "Thinking in pictures," comments on the belief held by some researchers that people with ASD are not capable of understanding deception. She finds it very difficult to understand how others practise deception, but with work she can do it.

Theory-of-Mind study influences and contributes to special education, so it is important to review Theory-of-Mind research with atypically developing populations from a special education perspective. This paper adopts the two models, psychological and interactionist, introduced by Riddell, Brown and Duffield (1995), with which to view disability, and emphasises the need for balance between them through a reflective and flexible approach to research attitudes, methods and material.

The traditional psychological view of disability is based on the premise that there exists a problem or deficit within a child, and is focused only on the impairment. The interactionist view is based on the premise that disability must be understood as a social construction, and focuses on the relationship of environmental factors to disability (Riddell et al., 1995). However, these two approaches complement rather than compete with each other. The psychological approach is useful for recognising problems, but does not provide a foundation for recognising possible strengths and drawing out educational strategies through a particular environment. The interactionist approach can develop such strategies, but without clearly identifying problems cannot get started.

Traditional Theory-of-Mind study seems close to psychological approaches to disability, with its focus on Theory-of-Mind deficit in children. But from here, where can we go? Interactionist approaches open up a number of possibilities to developing research 
methods that are both reflective and flexible. A reflective approach seeks to match each research task with the needs or difficulties of the individual participant. A flexible approach seeks to allow a variety of tasks and materials to accommodate the full range of needs and difficulties of each participant.

A reflective attitude may begin with a determination to not take ASD or disability for granted as a predefined category. As Temple Grandin (2006) points out, individual differences exist among people with ASD, and among disabilities in general. A reflective and flexible attitude allows participants in experiments to respond through a variety of communication forms (Davis, Watson, \& CunninghamBurley, 2000; Lewis, 1996), whether oral or written, or choose their own way to answer questions. Participants can then communicate in ways that are most natural for them, depending on their particular needs. In terms of flexibility, getting to know researchers before answering questions is particularly important for the ASD population. It is also important to avoid questions that require yes or no answers only, or which rely on very precise answers (Lewis, 1996).

A reflective and flexible approach needs to be applied to research materials. It is advisable, for example, to use age appropriate material in experiments, although Theory-of-Mind study has paid little attention to this aspect. For example, two sets of plastic playmobil dolls and soft plastic dolls were used for teaching Theory-of-Mind to individuals with autism who had a mean chronological age of 17:9, ranging from 8:6 to 28 (McGregor et al., 1998).

Research attitude is even more fundamental to a reflective and flexible approach. Moore, Beazley and Maelzer (1998, p.15) suggest that researchers ask themselves "Who do we want to value our research?" before and during research. Such reflection can extend to the role of the researcher and his/her relationship to participants. Historically, disabled people have been excluded, devalued and represented in largely passive and negative terms (Clough, 1995), and Theory-of-Mind study is not an exception. But such attitudes to atypically developing people can result in a crude approach to research, and so compromise research results.

\section{Conclusion - An Interdisciplinary Approach}

Theory-of-Mind study has been investigated in terms of its history, its philosophical background and its application to special education. Different concepts of mind, and different approaches to the understanding of reality, have been examined, and their implications for methodology have been drawn out.
The complexity of the human mind requires a model that can deal with that complexity. A Theoryof-Mind continuum model is based on an interdisciplinary approach embracing a dialogue between three disciplines; philosophy, psychology and special education. Philosophy provides the foundation for developing a view of the nature of mind, and of the world known by the mind. Psychology, especially developmental psychology, draws pictures of the development of mental states, indicating their variety and complexity. Education, particularly special education, is located between psychology and philosophy, drawing from both and applying their insights to the inner and social worlds of students, mediating between publicly held knowledge and the personal questioning of students (Pring, 2000).

As Pring (2000) points out, education mediates between the public world of social knowledge and the inner world of personal experience. In order to do this, both worlds must be understood. Up to now, Theory-of-Mind studies and interventions have put more emphasis on social knowledge than the inner experience of the subjects studied. To create effective educational interventions for students with disabilities we need to know more than whether or not they possess Theory-of-Mind. We also need to know how the world appears from the perspective of these students. Redressing this imbalance by studying the inner experience of students with ASD regarding Theory-of-Mind will provide insights into how to develop their Theory-of-Mind understanding.

Finally, it is important to avoid oversimplifying in our search for certainty. For example, it is commonplace to use the computer as a metaphor for the mind. This simplifies the complexity of mind so that it can be understood theoretically. However, while such metaphors can be useful, it is important to remember that mind is not a computer. The image is not the reality. The continuum model is another image, one that seems most useful in shedding light on the problems and possibilities for the development of Theory-of-Mind in students with ASD. But in the final analysis, (special) educationalists work with the reality of their students, and the metaphors and images of philosophers and psychologists must not be allowed to get in the way of the actual human encounter between teacher and student. What is important is keeping in mind the question, "What is good for our students?"

\section{Acknowledgement}

I (Yoon-Suk Hwang) am grateful to Patrick Kearney for his contributions to this paper as critic, editor and husband. 


\section{References}

Astington, J. W. (1994). The child's discovery of the mind . London: Fontana.

Astington, J. W. (2001). The future of Theory-of-Mind research: Understanding motivational states, the role of language, and real-world consequences. Child Development, 72, 685-687.

Astington, J. W., \& Barriault, T. (2001). Children's theory of mind: How young children come to understand that people have thoughts and feelings. Infants and Young Children, 13, 1-12.

Baron-Cohen (1995). Mindblindness: An essay on autism and theory of mind. Cambridge, MA: MIT Press.

Baron-Cohen, S., Campbell, R., Darmiloff-Smith, A., Grant, J., \& Walker, J. (1995). Are children with autism blind to the mentalistic significance of the eyes? British Journal of Developmental Psychology, 13, 379-398.

Baron-Cohen, S., Leslie, A. M., \& Frith, U. (1985). Does the autistic child have a "theory of mind?" Cognition, 21, 37-46.

Bartsch, K., \& Wellman, H. M. (1995). Children talk about the mind. New York: Oxford University Press.

Bauminger, N. (2002). The facilitation of social-emotional understanding and social interaction in high-functioning children with autism: Intervention outcomes. Journal of Autism Developmental Disorders, 32, 283-298.

Bauminger, N., \& Kasari, C. (1999). Brief report: Theory of mind in high-functioning children with autism. Journal of Autism and Developmental Disorders, 29, 81-86.

Bergen, D. (2002). The role of pretend play in children's cognitive development. Early Childhood Research and Practice, 4, 2-13.

Blackshaw, A., Kinderman, P., Hare, D., \& Hatton, C. (2001). Theory of mind, causal attribution and paranoia in Asperger syndrome. Autism, 5, 147-163.

Bosacki, S., \& Astington, J. W. (1999). Theory of mind in preadolescence: Relations between social understanding and social competence. Social Development, 8, 237-255.

Brent, E., Rios, P., Happé, F., \& Charman, T. (2004). Performance of children with autism spectrum disorder on advanced theory of mind tasks. Autism, 8, 283-299.

Brown, J., \& Whiten, A. (2000). Imitation, theory of mind and related activities in autism. An observational study of spontaneous behaviour in everyday contexts. Autism, 4, 185-204.

Carruthers, P., \& Smith, P. K. (1996). Introduction. In P. Carruthers, \& P. K. Smith, Theory of theories of mind (pp.1-8), New York: Cambridge University Press.

Chalmers, D. J. (1996). The conscious mind: In search of a fundamental theory. New York: Oxford University Press.

Charman, T., \& Baron-Cohen, S. (1995). Understanding photos, models, and beliefs: A test of the modularity thesis of theory of mind. Cognitive Development, 10, 287-298.

Chin, H. Y., \& Bernard-Opitz, V. (2000). Teaching conversational skills to children with autism: Effect on the development of a theory of mind. Journal of Autism Developmental Disorders, 30, 569-583.

Clough, P. (1995). Problems of identity and method in the investigation of special educational needs. In P. Clough \& L. Barton, Making difficulties. Research and the construction of SEN (pp.126-143). London: Paul Chapman Publishing.

Cohen, C., Manion, L., \& Morrison, K. (2002). Research Methods in Education (5th edition), London, New York: RoutledgeFalmer.

Davis J., Watson, N., \& Cunningham-Burley, S. (2000). Learning the lives of disabled children: Developing a Reflective approach. In P. Christensen \& A. James. Research with children (pp. 201-224). London: Falmer Press.

Dennett, D. C. (1978). Beliefs about beliefs. The Behavioural and Brain Science, 4, 568-570.

Dorris, L., Espie, C.A.E., Knott, F., \& Salt, J. (2004). Mind-reading difficulties in the siblings of people with Asperger's syndrome: Evidence for a genetic influence in the abnormal development of a specific cognitive domain. Journal of Child Psychology and Psychiatry, 45, 412-418.

Flavell, J. H. (2004). Theory-of-Mind development: Retrospect and prospect. Merrill-palmer Quarterly, 50, 274-290.

Fodor, J. A. (1983). The modularity of mind: An essay on faculty psychology. Cambridge, Mass: MIT Press.

Fodor, J. A. (1985). Fodor's guide to mental representation: The intelligent auntie's vade-mecum. Mind, New Series, 94, 76-100.

Frith, U., Happé, F., \& Siddons, F. (1994). Autism and theory of mind in everyday life. Social Development, 3, 108-124.

Frye, D. (1991). The origins of intention in infancy. In D. Frye \& C. Moore (Eds.), Children's theories of mind: Mental states and social understanding (pp.15-38), New Jersey: Lawrence Erlbaum.

German, T. P., \& Hehman, J. A. (2006). Representational and executive selection resources in 'theory of mind': Evidence from compromised belief-desire reasoning in old age. Cognition, 101, 129-152.

Glasersfeld, E. V. (1995). Radical Constructivism: A way of knowing and learning. London, Washington, D.C.: The Falmer Press.

Gopnik, A. (1996). Theories and modules; creation myths, developmental realities, and neurath's boat. In P. Carruthers, \& P. K. Smith, Theory of theories of mind (pp.169-183), New York: Cambridge University Press.

Gopnik, A., Capps, L., \& Meltzoff, A. N. (2000). Early theories of mind: What the theory theory can tell us about autism. In S. Baron-Cohen, H. Tager-Flusberg, \& D. J. Cohen, Understanding other minds. Perspectives from developmental neuroscience. (pp. 50-72). New York: Oxford University Press.

Gopnik, A., Slaughter, V., \& Meltzoff, A. (1994). Changing your views: How understanding visual perception can lead to a new theory of the mind. In C. Lewis, \& P. Mitchell, Children's Early understanding of mind: Origins and Development (pp.157-181), London: Lawrence Erlbaum.

Grandin, T. (2006). Thinking in pictures and other reports from my Life with autism. New York: Vintage books.

Grayling, A. C. (1995). Philosophy a guide through the subject, Oxford, New York: Oxford University Press. 
Hadwin, J., Baron-Cohen, S., Howlin, P., \& Hill, K. (1997). Does teaching theory of mind have an effect on the ability to develop conversation in children with autism?. Journal of Autism and Developmental Disorders, 27, 345-365.

Happé, F. (1994). An advanced test of Theory of Mind: Understanding of story characters' thoughts and feeling by able autistic, mentally handicapped and normal children and adults. Journal of Autism Developmental Disorders, 24, 129-154.

Hughes, C., \& Leekam, S. (2004). What are the links between theory of mind and social relations? Review, reflections and new directions for studies of typical and atypical development. Social Development, 13, 590-619.

Jolliffe, T., \& Baron-Cohen, S. (1999). A test of central coherence theory: Linguistic processing in high-functioning adults with autism or Asperger syndrome: Is local coherence impaired?. Cognition, 71, 149-185.

Kerr, S., \& Durkin, K. (2004). Understanding of thought bubbles as mental representations in children with autism: Implications for theory of mind. Journal of Autism and Developmental Disorders, 34, 637-648.

Leekam, S., Baron-Cohen, S., Perrett, D., Milders, M., \& Brown, S. (1997). Eye-direction detection: A dissociation between geometric and joint attention skills in autism. British Journal of Developmental Psychology, 15, 77-95.

Leslie, A. M. (1988). Some implications of pretense for mechanisms underlying the child's theory of mind. In J. W. Astington, P. L. Harris, \& D. R. Olson (Eds.), Developing theory of mind (pp.19-46), New York: Cambridge University Press.

Lewis, A. (1996). Children's understanding of disability. London, New York: Routledge.

McAlpine, L., \& Moore, C. (1995). The development of social understanding in children with visual impairments. Journal of Visual Impairment, 89, 349-358.

McGregor, E., Whiten, A., \& Blackburn, P. (1998). Teaching theory of mind by highlighting intention and illustrating thoughts: A comparison of their effectiveness with three-year-olds and autistic individuals. British Journal of Developmental Psychology, 16, 281-300.

Meltzoff, A. N. (1999). Origins of theory of mind, cognition and communication. Journal of Communication Disorders. 32, 251-269.

Moore, M., Beazley, S., \& Maelzer, J. (1998). Researching disability issues. Buckingham, Philadelphia: Open University Press.

Nagel, T. (1986). The view from nowhere New York, Oxford University Press.

Nazeer, K. (2006). Send in the idiots. Stories from the other side of autism. New York: Bloomsbury.

O'Connor, D. J., \& Carr, B. (1982). Introduction to the theory of knowledge. Brighton: Harvester.

Ozonoff, S., \& McEvoy, R. (1994). A longitudinal study of executive function and theory of mind development in autism. Development and Psychopathology, 6, 415-431.

Ozonoff, S., \& Miller, J. N. (1995). Teaching theory of mind: A new approach to social sills training for individuals with autism. Journal of Autism Developmental Disorders, 25, 415-433.

Peterson, C., \& Siegal M. (2000). Insight into Theory of Mind from Deafness and Autism. Mind \& Language, 15, 123-145.

Peterson, C., Peterson, J., \& Webb, J. (2000). Factors influencing the development of theory of mind in blind children. British Journal of Developmental Psychology, 18, 431-447.

Premack, D., \& Woodruff, G. (1978). Does the chimpanzee have a "theory of mind"? The Behaviour and Brain Sciences, 4, 515-526.

Pring, R. (2000). Philosophy of education research. London, New York: Continuum.

Pylyshyn, Z. W. (1978). What is attribution of beliefs justified? The Behaviour and Brain Sciences, 4, 592-593.

Ravenscroft, I. (2005). Philosophy of mind: A beginner's guide. New York: Oxford University Press.

Riddell, S., Brown, S., \& Duffield, J. (1995). The ethics of policy-focused research in special educational needs. In P. Clough, \& L. Barton, Making difficulties. Research and the construction of SEN (pp.126-143). London: Paul Chapman Publishing.

Sally, D., \& Hill, E. (2006). The development of interpersonal strategy: Autism, theory-of-mind, cooperation and fairness. Journal of Economic Psychology, 27, 73-97.

Sicotte, C., \& Stemberger, R. (1999). Do children with PDDNOS have a theory of mind? Journal of Autism and Developmental Disorders, 29, 225-233.

Sparrevohn, R., \& Howie, P. M. (1995). Theory of mind in children with autistic disorder: Evidence of developmental progression and the role of verbal ability, Journal of child psychology and psychiatry, 36 (2), 249-263.

Steele, S. Joseph, R. M., \& Tager-Flusberg, H. (2003). Developmental change in theory of mind abilities in children with autism. Journal of Autism and Developmental Disorders, 33, 461-467.

Swettenham, J. G., Baron-Cohen, S., Gomez, J-C., \& Walsh, S. (1996). What's inside someone's head? Conceiving of the mind as a camera helps children with autism acquire an alternative to a theory of mind. Cognitive Neuropsychiatry, 1, 73-88.

Wimmer, H., \& Perner, J. (1983). Beliefs about beliefs: Representation and the constraining function of wrong beliefs in young children's understanding of deception. Cognition, 13, 103-128.

Yirmiya, N., Erel, O., Shaked, M., \& Solomonica-Levi, D. (1998). Meta-analysis comparing theory of mind abilities of individuals with autism, individuals with mental retardation, and normally developing individuals. Psychological Bulletin, 124, 283-307. 


\section{About the Authors}

Yoon-Suk Hwang

Yoon-Suk Hwang worked for three years as a special education teacher of a support class in a public primary school in the Republic of Korea. She is currently a Ph.D. candidate in the Faculty of Education and Social Work, The University of Sydney. Her Ph.D. concerns Theory-of-Mind in Autism Spectrum Disorder (ASD) as experienced from within by the ASD population and observed from without by their teachers. Her areas of interest are philosophy of educational research, self-determination and inclusive education for students with and without disabilities.

\section{Dr. David Evans}

David Evans is currently Associate Professor of Special Education in the Faculty of Education and Social Work at the University of Sydney. Over the past twenty years he has taught in regular and support classes across primary and secondary schools in New South Wales, Western Australian, the Northern Territory and South Australia. He has also had university appointments at Edith Cowan University (Western Australia) and the University of Western Sydney. Current research programs include education of students with autism, literacy and numeracy difficulties, educating students with chronic illness and brain injuries, and whole school approaches to managing diverse learning and behavioural needs. Address: Associate Professor David Evans, Faculty of Education and Social Work A35, the University of Sydney, NSW, 2040, Australia.

\section{Dr. Jim Mackenzie}

Jim Mackenzie is a Senior Lecturer in Philosophy of Education in the Faculty of Education and Social Work at the University of Sydney. His interests include the logic of dialogue, the history of educational ideas, curriculum structure, and crap detection. 